Case 5.-W. B., a boy aged 12 , stopped on the sidewalk to tie his shoestrings. On attempting to set one foot on a step, the other slipped from under him, causing him to fall backward, striking the occiput violently on the pavement. There were symptoms of concussion, lasting several hours. In a short time epilepsy developed and continues to the present in an aggravated form.

Case 6.-J. F., aged 8, fell from a swing, striking the head upon a stone, lacerating the scalp and producing symptoms of shock which lasted several hours. There were no symptoms of compression nor fracture. Recovery was apparently perfect. At the age of 18 epilepsy developed and continued for about three years, becoming more and more violent until death.

Case $7 .-J$. R., at the age of 5 , fell from a fence, receiving a blow upon the head, producing violent shock, and was in a state of stupor for several days. At the age of 16 epilepsy developed and continues to the present.

Without reciting each case similar in most respects to the foregoing, I can call to memory many other cases of injury in whom no history of heredity, specific disease or reflex neuroses of any character whatever can be traced as a cause.

Younger children, in my judgment, are in danger of epilepsy upon meeting with what may be termed every-day casualties, as falling down stairs, out of the ligh chair, off the bed to the floor. from the porch to the pavement and other similar accidents where the head receives the blow.

I can recall quite a number of epileptics in boys and girls to whom I was called at the time of such accidents as spoken of above at the crawling age of childhood. Some of the worst epileptics I have seen have no history of cause beside the fall and consequent injury to the head of the infant.

Meddlesome midwifery, it is to be feared, must be held responsible for some cases, the most wretched and hopeless we are called upon to witness, the forceps having inflicted injury to the head.

Prof. Chas. D. Meigs in his day, foreseeing the tendency to wantonly use the forceps, charged his pupils to remember that the best obstetrician was be who stood by his patient with his hands folded behind him.

There are dystocias when the forceps must be used, when it would be criminal to not use them, though epilepsy in the child be sure to follow. The point is this, that the utmost skill and care should be used to avoid injury to the fetal head lest epilepsy may develop in the child.

I have seen two cases, not my own, it is reasonably certain resulted from injury in forceps delivery, and two more strongly suspected to owe their origin to the same cause, every other history of cause being absent.

My experience is largely among rural people where the forceps are not often required or resorted to, and where of course epileptic results would be rare from such a cause, but if two cases come under the obserration of each city and country physician during a quarter of a century, see what a vast army of epileptics follow in the wake of the forceps. Epilepsy merits the attention of the physician from every standpoint. Large numbers of epileptics are in every locality. They are of all people the most unfortunate. Too much can not be known concerning it. How impotent all physicians confess themselves to be when confronted with it.

In cases from trivial reflex causes treatment may be successful. In confirmed cases medicines avail so little that both physician and patient tire of treatment.

The surgeon on account of so small percentage of favorable results in the most hopeful cases operated upon is held at bay. So the most rational procedure is to adopt preventive measures.

If heredity, insanity, inebriety, specific infection and so on among the ancestors are found to be causes, the gravity of the affection demands that means be employed to curtail the transmission of the disease to posterity. Knowing injuries to the head to be a fruitful source, all should unite every effort to teach and impress upon parents and others in charge of children to use all precautions possible to protect the child's head from every sort of injury, epilepsy having been known to follow what seemed to be a slight injury to the head. It is not the purpose to speak of any theory of pathology or morbid anatomy.

The literature upon the disease is enriched by the observations of eminent men in every age and country. The same views are not long held by any student, for experiments and postmortems are likely to revolutionize any theory previously announced.

Most writers regard traumatism overestimated as an exciting cause. Experiments of any kind that disturb the cardiac or cerebral functions may excite convulsions and establish any theory desired.

In relating cases I selected those in whom a record in the ancestral line, of heredity, insanity, inebriety, tuberculosis or specific infection did not exist, so that the fact of injury alone could remain as the factor, the kind of injury that can be in a great measure avoided by watchful care in the rearing of children.

\section{PETIT MAL IN CHILDREN.}

Read in the Section on Diseases of Children, at the Forty-seventh Annual Meeting of the American Medical Association, held

\section{BY LOUIS FAUGÈRES BISHOP, A.M., M.D.} NEW YORK.

Idiopathic epilepsy is eminently a disease of children, occuring in more than three-fourths of the cases before the twentieth year. So much is this true, that in epilepsy in older people, we always institute a special search for a local cause. Of the causes of epilepsy we are not to treat in this place, nor indeed of the typical severe cases, but because we separate petit mal, we must not fall into the error of supposing we have to deal with a different disease. Nor is it always easy from the description of parents, when there is no opportunity of observing the attacks, to be sure into which group the particular case should go.

Though not a common form of manifestation of epilepsy in children still among a large number of cases there will be a certain number in which the disease at least in its onset takes this form. On account of its comparative rarity and because of the proneness of young children to convulsive attacks of various kinds whose etiology is clearly to be found in local irritation, these minor attacks of epilepsy are seldom recognized by those whose attention has not been particularly called to the subject.

There are certain physiologic considerations that must have weight in our diagnosis. Up to about three years it is difficult to make the diagnosis of petit mal because the physiologic irritability of the nervous system is so great that we can not exclude a sufficient cause of irritation. After about the age of three years the nervous system has obtained a degree or stability that makes the frequent recurrence of con. vulsive seizures an indication of epilepsy. Of course, if there is a family history of a tendency to such 
attacks at a later period, which have not proved to be epileptic, this circumstance must be given due weight. As in older people we must exclude kidney disease and injuries to the brain.

In addition to a due appreciation of this period of irritability we need to have a more symmetric comprehension of epilepsy. Petit mal is not one disease and grand mal another, but they are different manifestations of the same disease. It is for the sake of emphasizing petit mal to the dignity of true epilepsy that this study of that particular form of epilepsy in children has been undertaken. The attack of petit mal is a sudden temporary unconsciousness, often accompanied by certain other phenomena. In a large number of cases the eyes become fixed, the face pale, and in a moment the patient assumes his ordinary conditions; in others, the patient talks in a wild manner, often upon some subject entirely disconnected with the surroundings present. The patient may perform some curious automatic action, or go through with some particular act while in the epileptic state.

A very curious case came to the Vanderbilt Clinic, New York City, a few days ago. The child, 7 years old, had frequent attacks in which she suddenly seized her head by the hair on either side. and then there was a jerky motion of the arms and head, at the same time one foot was raised as high as possible and the child would stand for a moment on the other, but if not supported, would fall. This occurred while under observation about every fifteen minutes. The child was unconscious during the early part of the attack, which lasted probably during the fraction of a minute. Another child also seen at the Vanderbilt Clinic recently, suffered a compound fracture of the skull a years ago. A few weeks ago she developed attacks, which come on every night about ten o'clock, after she had been in bed an hour or two. She wakes out of her sleep in a fright, and almost immediately becomes rigid and apparently unconscious.

An attack of petit mal may assume a great variety of forms. A mere momentary blurring and loss of consciousness at frequent but irregular intervals, or sudden sensations of fright without apparent cause, or a feeling of something in the epigastrium and rising in the throat. Thus in a case coming under observation while preparing this paper, a child of five years old had convulsions during the first two or three months of life, and since that time had been subject to attacks at intervals, the mother says "a thousand a dicy," during which the child's head sudclenly drops, the arms are stiffened, and after an attack of momen. tary unconsciousness the child goes on as before. Such a case is of sufficient severity to attract the attention of a physician, and to make a diagnosis perfectly easy, but it can be seen that attacks of the same nature occurring at infrequent intervals, and of which we have only the account of parents, would nearly always be disregarded. When associated with grand mal, or when it has been followed by grand mal later on, the diagnosis of true epilepsy is of course very much more certain; still when studied carefully these cases assume a certain definiteness, which it is hard to convey by a written description.

The diagnosis must rest on the recurrence of the attacks irrespective of gastric irritation, the fact that they are not cured by the removal of sources of irritation, the persistence of the type of the attacks and the occasional recurrence even in quite young children of the epileptic equivalent, i.e., periods, during which instead of loss of consciousness, the patient does and says things entirely disconnected with the time and place. The attacks must be distinguished in very young children, first of all from convulsive seizures due to local irritation. As we said before, under three years except in very well marked cases this can hardly be done.

Simple vertigo may resemble petit mal but the affection of consciuusness is usually described as somewhat different. In vertigo there is a characteristic feeling as if objects were whirling around. The child says, "the house is going around." In epilepsy there is more the sensation of simple blurring or confusion. Vertigo is preceded by a period of weakness, while the onset of petit mal is always sudden. The patient is stiff for a moment, stares, and there is a momentary loss of consciousness, but the attack passes over as suddenly as it came, and he goes on with the occupation in hand. In vertigo the body is limp and the process is more gradual. In petit mal the pupils are dilated and the eyes immobile. We must distinguish hysteria, which occurs frequently enough in children. This may be done by the tightly closed eyes, the tremulous lids, the persistent rigidity, but especially by the existence of hysteric attacks of other types. Petit mal may occur every few moments for years without changing its form of attack. Of course, this rule is not without exception. Thus in a young person at present under observation attacks of petit mal are sometimes replaced by short outbreaks of ill temper, which are entirely foreign to her ordinary disposition.

While we have begged the question of a certain diagnosis of petit mal during the first three years of age, yet cases from time to time have come under observation in which a study of the particular case has convinced us that it was one of true epilepsy. Its frequency during this period of life is shown by the statistics of Gowers, who found that $12 \frac{1}{\text { s }}$ per cent. of all epileptics had developed the disease before three years, and of these one-half had developed during the first year of life. In our own histories we find fairly frequent instances of fully developed epilepsy in later life having originated as petit mal in children. This history is brought out more often if, as with us during the last few months, we have inquired particularly for symptoms of petit mal antedating the onset of convulsions. It would seem especially interesting to inquire as to the early existence of petit mal, in those cases in which under treatment, petit mal is substituted for the typical severe convulsions. Some of these cases impress one as if the attack of petit mal was a development of an epileptic aura, which stopped short of the convulsion. In some very rare cases there has been a distinct sensory aura preceding the attack of petit mal.

Petit mal is essentially a chronic disease, and for that reason it is difficult to formulate the best plan of treatment. However, special stress should be laid upon the care of the stomach and all those measures which are included under the name of hygienic management. As to drugs there has been a great variety recognized. Petit mal is more intractable than the severer convulsions, but the same treatment which has been found best in these has on the average given the best results in petit mal. After experimenting with a great variety of drugs it has seemed that bromid in moderate doses has given on the average the best results. Occasionally a case has shown 
improvement when under nitro-glycerin. Belladonna in our hands has never given any results, and the same is true of borax, digitalis, and a number of other drugs.

If our conception of epilepsy as a stormy and ungoverned discharge of the motor cells of the brain be a true one, which belief is strengthened by the fact that seizures are more likely to take place in those who have been sleeping, or who habitually sleep too much, why would it not be possible by systematic training of these cells to diminish the liability to such outbreaks? Systematic exercise of such a varied kind as would exercise all the muscles of the body might thus have such an effect beyond that due to the mere improvement of the general physical condition.

The parents of the child should know of the very possible persistence of the affection into adult life, so that everything should be done to render the disease as bearable as possible to the little patient. The friends and attendant should be instructed to speak as seldom as possible of the attacks to the child, and should be thoroughly instructed that attacks of petit mal are entirely beyond the control of the patient. An effort should be made to treat the child as nearly as possible as other children, not restricting it of its liberty, or treating it like an invalid in any way, except as far as is necessary to carry out the proper regimen and treatment.

DISCUSSION ON PAPERS OF DRS. MIXON AND BISHOP.

Dr. Thomas H. Manley, New York-You know how unsatis factory and discouraging the teaching of obstetrics to the medical student has been. It has often occurred to me it would be better for humanity if we had no such science as the art of midwifery. You will remember it was claimed the mortality from sepsis had been reduced to practically nothing, through the adoption of the antiseptic treatment, washing and flushing the vagina precedent and antecedent to confinement; and then, again, we have been taught later the position we are coming back to, the best thing. to do is to do nothing at all in the way of using solutions about those passages. The tendency is, that the ideal man is the one who can make a diagnosis without passing his finger in the vagina. Then we will not have to deal with a sepsis, because pathogenic germs do not normally belong in the vagina. When the forceps are used damage may be done in the way of lacerations and tears of the cervix, vagina and outlet, so far as the woman is concerned, by not allowing nature to gradually open the way and send the child along by slow and natural stages. Next, with reference to the child, I think the effect of the forceps is murderous, perhaps not at first but ultimately. You can not make me believe the strength of a man with the forceps locked on the fetal head, and perhaps a couple of women holding the women in the bed, will not injure the delicate structures of the fetal brain. In my own family, the only one who has manifested any nervousness, and now she is an adult, was the first born, in whom $I$ believe the physicians prematurely applied the forceps and damaged the head. I would not allow the forceps to be used on any of the others and they have no bad symptoms.

Now as to trauma as a cause of epilepsy. That has not been my experience, and for fifteen years, I was connected with a hospital in which traumatisms constituted perhaps four-fifths of the cases. In New York we have thousands of cases of traumatisms, from children falling from the fire-escapes. We have, consequently, many cases of skull injuries, but my experience has not been that trauma in itself is a cause of epilepsy. I have traced quite a number of cases, where it became necessary to trephine and elevate depressed bone; the children had veen brought in the ward perhaps unconscious, and I could not find in enough of cases the history pointing to trauma to convince me it was a positive etiologic factor in epilepsy as a general rule.

As to the surgical treatment of epilepsy; I have trephined quite a number, who had come into the hospital for that special purpose. After Professor Horstley's paper, which did great damage from claiming he could do what could not be done, I hoped something might be done for the epilepties and I trephined. In perhaps about a quarter of them I found those gliomatous tumors, the myxomatous substance between the dura mater and pia mater. Not in a single instance was there anything but temporary relief. I believe there is a question whether the relief was from the loss of blood, the opening of the scalp, the anesthesia, the psychic effect of the operation or what. If there is anything we owe to each other it is to be truthful. We can not get the facts unless we get the cases that do badly as well as those that do well, and I have Lot hesitated to go before my optimistic brethren in New York and ask them to show me one case which showed relief from operation. But if we have evidence of distinct depression of bone, it is very clear what the line of action should be. But otherwise I doubt the expediency of operation. We should not overlook the fact that these operations are not entirely innoxious. I have known more than one patient to lose his life from hemorrhage. When you start a hemorrhage in the brain, which is an extremely vascular organ, you can not stop it readily. You can not apply pressure without pushing a hole through the brain substance.

Dr. J. A. Work, Elkhart, Ind.-One point came to my mind during the reading of the first paper. The author did not say much about etiology in petit mal in children. It seems to me we ought to determine the primary cause of all this trouble. He said we should look well to the condition of the child's stomach, to the development of the child, to its food, its environments. It seems to me there is where the trouble originates in early infancy or childhood, when we consider that one-half of the deaths that occur are in children under 5 years of age. I say the same of the second paper read. We do not go back far enough in etiology. It has been my fortune to see cases of epilepsy that have orignated traumatically. I would like, if the Section would permit the time, to report one or two of these cases. One case was that of a soldier, on his way from Indianapolis to another point, who fell off a flat car and was not found for two or three days. When found, he was suffering from depression, $I$ think in the right parietal region. The history of the case was that the patient was unconscious for probabiy twenty-four hours. The later history of the case I had from his own lips. After returning from the army, although a molder by trade, he went into the study of law, about fifteen years after the injury, and he said from the time he recovered consciousness until I was in conversation with him he had not been void of pain in the region where the injury was received, except when he was asleep. I was called one morning early. He had gone to the cooking room to build a fire and was later found on the floor. This was the first attack he had had of epilepsy, some fifteen to twenty years after the injury. He seemed to recover as if he had awakened from a sleep, and wanted to know where he was, how he came there, etc. The attacks became more frequent, and he became more imbecile and died about two years after the firstattack. A postmortem was held. Under the dura mater, at the base of the brain, we found a tumor about the size of a turkey's egg, flattened out, which we supposed was the cause of the epilepsy and death.

A nother case was that of a soldier injured at Chickamauga by a shell. He lay on the field for some hours, and the surgeons pronounced his case hopeless. He finally recovered and served out his term in the army. But he said a stroke upon his forehead in the injured region, would bring on temporary insensibility. After his return home, while employed as a 
laborer, he fell down with epilepsy, and found he could not obtain employment because of his attacks, which occurred every two weeks. I saw him have an attack near my office. I thought he never would never recover from it. In two weeks, after preparatory treatment, I trephined and removed a three quarter inch disc. No evidence of fracture of the skull was found. The skull was very thick. In two weeks from that time he had a slight attack and that was the last. He died some ten years afterward of another disease. There was a case of cure, to all intents and purposes, by trephining.

Dr. Harold N. Moyer, Chicago, Ill.--I can not allow the opportunity to pass without making a remark or two upon the papers with reference to epilepsy. This disease is one of the most interesting in our pathology. I think we are apt to forget this is the morbus sacer, the sacred disease of history. I believe epilepsy is the oldest disease existing. I believe it began when the animals began to have nervous systems. Animals have the disease; cats are notoriously affected with it; horses have it under the name of "blind staggers ;" elephants have it without a doubt, and how far down the scale it extends it is impossible to say. It probably existed prior to the stone age, even prior to the time when man made his advent upon this earth. We understand it now no better than they did then. We absolutely know nothing about the pathology or the pathologic anatomy of epilepsy. We know nothing as to its etiology, more than the exciting causes which have been mentioned. Head injuries, the importance of which has been well brought out, I consider furnish many cases of epilepsy. There are doubtless many other causes, but it is well to remember these are merely exciting causes. Many children receive injuries who do not develop epilepsy. Why do those who receive these injuries not have epilepsy? The difficulty is that the underlying etiologic factor in epilepsy is absolutely unknown to us. If we understood that, we would know its pathology. When we come to the question of treatment, the same thing applies; not knowing the pathology and etiology, the treatment must necessarily be vague. But I wish to emphasize the statements made by Dr. Manley. Operations for epilepsy undertaken indiscriminately because the patient is epileptic, should be discouraged. I believe it is almost malpractice to operate in these cases, for you thereby add a very severe trauma. I want to be understood in the proper sense, for it would not be malpractice if the operation is demanded by some injury, depressed bone, etc. But otherwise I have never recommended skull operations except in the form known as Jacksonian epilepsy where the center could be well localized. I believe the literature of the subject justifies very strong statements on this question.

The paper by Dr. Bishop is very interesting. The Doctor was kind enough to give us his diagnostic rules. I confess as I listened to him I thought I would be able now to make a diagnosis of epilepsy in childhood with some precision, but I fear I will not be able to apply the lines he has laid down. But there is one good rule, which I shall substitute for those given by the Doctor, and that is if $I$ have brought to me a young child in which I suspect epilepsy, I shall assume it is epilepsy and treat it as such. If it is not epilepsy, such treat. ment will do no harm; and if it is epilepsy in its incipiency, then is the time to do good with treatment. If there is any one rule in this disease, it is to begin treatment early. After the condition is confirmed, treatment is almost entirely hopeless. The petit mal is then more hopeless than the grand mal, because the petit mal is accompanied by changes in the brain which lead to early dementia and conditions leading to imbecility. Unfortunately, the treatment is not all that could be wished. I desire to emphasize the Doctor's remark, that the hygienic treatment is of the greatest importance. As to the medicinal treatment, I am a firm believer in the bromid of sodium and use no other salt. I do not mean to say that you should simply pour in this remedy and you will secure good results, for one-third will not tolerate it, another third will be benefited, and another third will be indifferent to the treatment. But I believe this bromid is better than any of the others, and it is much better borne than the bromid of potas. sium. If it is given two hours after meals and well diluted, and the patient is frequently bathed, very considerable doses can be given without producing bromism. The bromid of sodium given within the tolerance of the patient and begun early I believe is the most efficient treatment.

\section{OPTIC NERVE ATROPHY FROM TOXIC AGENTS.}

Read in Discussion on Optic Nerve Atrophy in the Section on Ophthalmolory, at the Forty-seventh Annua Meeting of the American Medical Association. held at Atlanta, Ga. May $5-8,1896$.

\section{BY G. E. DE SCHWEINITZ, A.M., M.D.} PHILADELPHIA.

Toxic optic nerve atrophy naturally includes, 1 , those cases of atrophy which result from a direct action of the poisonous substance, or its systemic results, upon the nerve cells, the nerve fibers or their vascular supply, and, 2, those cases of atrophy which are secondary to retino-choroidal or constitutional changes, which in their turn have been called into existence by toxic agents.

The first class is separable into three subdivisions, namely, $a$, partial atrophy of the optic nerve with special reference to degeneration of its papillo-macular bundle, $b$, scotomatous atrophy of the optic nerve, which is progressive and may become total, and $c$, general atrophy of the optic nerve.

1. Toxic atrophy of the papillo-macular bundle of the optic nerve preceded by inflammation or degenerative changes in this tract and associated with scotoma.-Cases of this class manifest themselves either in the form of a chronic retro-bulbar neuritis, or else as an intoxication-amblyopia, because we may with propriety draw a clinical distinction between these two manifestions, although anatomico-pathologically they are in close accord, the intoxication-amblyopia, as Groenouw puts it, being a special form of retrobulbar neuritis.

A.xinl neuritis, a term sometimes employed, according to the same author, should be reserved for those cases characterized by a lesion, confined to the papillomacular bundle where it is axial in its course.

Following Groenouw ${ }^{1}$, the papillo-macular bundle may be described as consisting of those fibers in the optic nerve which supply the retina between the macula lutea and the papilla, and which lie in the temporal portion of the nerve tip, in a wedge-shaped segment. The apex of this triangular portion is directed toward the vessels and occupies about onethird of the surface of the papilla. As it pursues its way through the orbital portion, it gradually approaches the axis of the nerve, which it reaches in the optic canal. At the foot of the chiasm it occupies its upper and inner portion, but in the tractus it sinks to the central portion and remains there until it arrives at the brain.

According to Sachs', the papillo-macular bundle in the papilla is a triangle with its apex at the vessels, and the base toward the supero-temporal quadrant. Going backward, the bundle becomes elongated and assumes a crescentic form as it nears the optic canal. It would not be profitable at present to discuss the

1 Graefe's Archiv, 1892, xxxvii, Abth. I, pp: 170

2 Archlyes of Ophthalmology, is89, xviii, No.2. pp $133 \cdot 162$ 